\title{
Identifikasi Amplitudo dan Sudut Kedatangan Sinyal Menggunakan Metode Forward-Backward APES pada Radar Multi-Antena
}

\section{Identification of Amplitude and Direction- of-Arrival for Signals Using Forward- Backward APES Method on Multi-Antenna Radar}

\author{
Sapriansa, Syahfrizal Tahcfulloh* \\ Jurusan Teknik Elektro, Fakultas Teknik, Universitas Borneo Tarakan \\ Jl. Amal Lama No.1, Tarakan 77123 \\ sapriansaa@gmail.com, rizalubt@gmail.com*
}

\begin{abstract}
Abstrak - Jenis sistem radar multi-antena ada dua macam yaitu phased-array (PA) dan Multiple-input Multiple-Output (MIMO). Parameter yang digunakan untuk menguji kinerja radar PA dan MIMO ada banyak sekali yang salah satunya adalah estimasi parameter yang berkaitan dengan jumlah target deteksi. Estimasi parameter termasuk di dalamnya yaitu sudut kedatangan sinyal (direction of arrival, DoA) dan amplitudo sinyal pantulan. Penelitian ini mengusulkan perluasan dari pendekatan estimasi parameter yaitu amplitudo and phase estimation (APES) yang dinamakan forward-backward APES (FBAPES). Pendekatan ini memberikan perbaikan resolusi terhadap estimasi amplitudo dan DoA dari sinyal pantulan target radar yang dikomparasikan dengan estimator konvensional seperti least squares (LS). Formulasi dan evaluasi kinerja estimator yang diusulkan akan diuji berdasarkan berbagai faktor seperti besar radar cross section (RCS), resolusi sudut antar dua target, dan jumlah elemen antena di transmitter-receiver (Tx-Rx). Resolusi sudut deteksi yang diperoleh untuk estimator ini lebih baik dari estimator $L S$, sebagai contoh untuk $M=N=8$ maka diperoleh resolusi sudut $3^{\circ}$ sedangkan estimator $L S$ sebesar $5,8^{\circ}$.
\end{abstract}

Kata Kunci: Amplitudo and phase estimation (APES), estimasi parameter, phased-array, radar MIMO.

Abstract - There are two types of multi-antenna radar systems, i.e. the phased-array (PA) and the
multiple-input multiple-output (MIMO). There are many parameters used to test the performance of the
$P A$ and the MIMO radars, one of which is parameter estimation related to the number of detection
targets. Estimated parameters include the angle of arrival of the signal (direction of arrival, DoA) and
the amplitude of the reflected signal. This study proposes an extension of the parameter estimation
approach, namely amplitude and phase estimation (APES), which is called forward-backward APES
(FBAPES). This approach provides improved resolution of the amplitude and DoA estimates of the
reflected radar target signal compared to conventional estimators such as least squares (LS). The
formulation and evaluation of the performance of the proposed estimator will be carried out based on TELKA, Vol.7, No.2, November 2021, pp. 89 99

ISSN (e): 2540-9123

ISSN (p): 2502-1982 
various factors such as variations in radar cross section (RCS), angular resolution between two targets, and the number of antenna elements in the transmitter-receiver $(T x-R x)$. The resolution of the detection angle obtained for this estimator is better than the LS estimator, for example for $M=N=8$ then the angle resolution is $3^{\circ}$ while the LS estimator is $5.8^{\circ}$.

Keywords: Amplitudo and phase estimation (APES), parameter estimation, phased-array, MIMO radar.

\section{Pendahuluan}

Seiring berkembangnya teknologi telekomunikasi maka berkembang pula kemajuan alatalat canggih dimana kemajuan tersebut menimbulkan tuntutan dari masyarakat yaitu kebutuhan perangkat dengan kapabilitas dan mobilitas tinggi sehingga perangkat telekomunikasi yang digunakan dapat menunjang segala aktivitas dengan sebaik mungkin, salah satunya yaitu teknologi radar. Radar adalah peralatan telekomunikasi yang berfungsi sebagia mata elektronik (electronics eye) yang menggunakan pancaran gelombang radio (radiowave). Radar yang dalam bahasa Inggris merupakan singkatan dari Radio Detection and Ranging yang dalam bahasa Indonesia disebut deteksi dan penjangkau melalui gelombang radio. Radar adalah suatu sistem gelombang elektromagnetik yang berguna untuk mendeteksi objek target, mengukur jarak (range) dan kecepatan target (Doppler shift), membuat peta dan citra dari benda-benda seperti pesawat terbang, informasi cuaca, dan masih banyak lagi. Berdasarkan lokasi dan kegunaanya, radar ada yang dipasang di pinggir pantai, di kapal, di pesawat udara, di bandara, dan pada tempat-tempat yang dirahasiakan.

Radar mampu berperan sebagai mata yang dapat melihat objek di kejahuan. Panjang gelombang (wavelength) yang dipancarkan radar adalah beberapa milimeter hingga satu meter. Dikarenakan kemampuan dan keunggulannya maka radar banyak digunakan untuk melihat objek di udara dan di laut yang daerah jangkauannya yang sangat jauh dan luas.

Dalam beberapa tahun yang lalu, muncul pengembangan teknologi di bidang radar multiantena. Sistem radar dengan multi-antena ini menggunakan array antena yang bertujuan mendapatkan gain dan bandwidth yang tinggi [1]. Radar multi-antena diawali dengan ditemukan radar PA. Radar PA adalah suatu sistem radar dengan semua elemen-elemen antena diatur fasenya sedemikian sehingga memiliki beam atau sorot pancaran radiasi gelombang elektromagnetik menuju ke arah target yang diinginkan [2]. Prinsip dari radar ini adalah berdasarkan pada pergeseran fase tiap elemen antena untuk memperoleh pantulan dari target yang sinyalnya terkuat. Maka dari itu radar ini dapat mendeteksi suatu target yang jauh dengan gain koheren tinggi dan memiliki RCS yang lemah atau kecil [2].

Pada sisi lain berkembang pula suatu sistem radar multi-antena baru yaitu radar MIMO. Radar MIMO ini mampu membentuk beam-beam transmisi pada tiap-tiap elemen antena dengan mengirim sinyal waveform yang bersifat independen atau ortogonal dari masing-masing elemen antena [3]. Sinyal waveform dari sistem radar ini yang bersifat ortogonal satu dengan lainnya dari beberapa antena pemancar atau Tx dapat memberikan keunggulan dengan waveform diversity gain yang tinggi. Bentuk sinyal waveform ini dapat diekstraksi oleh masingmasing antena Tx atau Rx dengan satu set filter yang cocok atau match filter (MF).

Banyak penelitian yang telah dilakukan terhadap kinerja dari radar PA dan MIMO seperti pada parameter-parameter yaitu beamforming pada $\mathrm{Tx}-\mathrm{Rx}$, gain pada $\mathrm{Tx}-\mathrm{Rx}$ dan signal to interference plus noise ratio (SINR), estimasi parameter, deteksi target, dan lain-lain [4]. Pada penelitian difokuskan pada identifikasi dan estimasi parameter pada radar PA dan MIMO. Beberapa metode estimasi parameter target pada radar tersebut telah diinvestigasi seperti metode LS [5-6] dan APES [7]. APES adalah pendekatan penyaringan adaptif yang disebut sebagai estimasi amplitudo dan fase dari sinyal sinusoida untuk estimasi spektral kompleks. Metode APES dapat menghasilkan perkiraan spektral yang lebih akurat baik pada amplitudo maupun sudutnya [8-10]. Namun metode APES yang diterapkan pada radar PA dan MIMO umumya berjenis forward yang dinamakan FAPES. Oleh karena itu kontribusi utama pada penelitian yang diusulkan ini adalah formulasi dan evaluasi estimasi parameter target APES 
yang berjenis FBAPES karena metode ini yang diteliti oleh [8] sepengetahuan penulis belum diterapkan pada aplikasi sistem radar multi-antena. Pada penelitian yang diusulkan ini akan mengestimasi parameter target dari sinyal echo pada amplitude dan fase yang dipengaruhi oleh beberapa faktor seperti besar RCS, resolusi sudut antar dua target, dan jumlah elemen antena di Tx-Rx.

\section{Metode Penelitian}

\subsection{Reviu Radar Multi-Antena}

Radar multi-antena adalah radar dengan konfigurasi banyak antena yang membentuk array baik di Tx dan Rx. Ada beberapa jenis radar multi-antena yaitu radar PA dan MIMO. Radar PA memiki keunggulan pada directional gain yang berguna untuk mendeteksi target yang lemah dan menekan level sidelobe ke arah datang interferensi [11]. Sementara radar MIMO telah diakui dapat memperbaiki resolusi radar karena memiliki keunggulan pada peragaman waveform yang tinggi [12]. Radar MIMO memiliki transmisi ke segala arah (omnidirectional) untuk setiap elemen Tx-nya tanpa membentuk suatu beam direksional [13]. Beampattern total pada radar MIMO merupakan hasil perkalian beampattern pada Tx dan $\mathrm{Rx}$ sehingga memberikan resolusi deteksi sudut yang tinggi [14]. Pada radar MIMO juga menunjukkan bahwa waveform yang dipantulkan oleh banyak target memiliki sifat yaitu independen secara linier sehingga mendukung penerapan banyak teknik estimasi adaptif. Teknik estimasi ini berguna untuk memperoleh resolusi yang tinggi sekaligus mampu menolak interferensi dan jamming.

Diasumsikan suatu sistem radar multi-antena dengan antena-antena yang co-located tersusun atas $M$-unit antena pada array Tx dan $N$-unit antena pada array Rx. Pada radar PA, sinyal pada Rx akan melewati MF untuk dipisahkan terhadap sinyal transmit menjadi vektor data $N \times 1$ yaitu [13]

$$
\mathbf{y}_{\mathrm{PA}}=\sum_{p=1}^{P} \sigma_{p}\left(\theta_{p}\right) \mathbf{u}_{\mathrm{PA}}\left(\theta_{p}\right)+\mathbf{n}_{\mathrm{PA}}
$$

dimana $\mathbf{u}_{\mathrm{PA}}(\theta)=\beta \mathbf{b}(\theta)$ yaitu vektor steering Tx-Rx, $\sigma_{p}(\theta)$ menyatakan amplitudo kompleks sinyal ditransmit dari target, $\beta$ merupakan gain direksional beampattern pada $\mathrm{Tx}, \mathbf{b}(\theta)$ adalah vektor perambatan $N \times 1$ yang terjadi karena delay perambatan dari Tx ke Rx, dan $\mathbf{n}_{\mathrm{PA}}$ adalah $N$ $\times 1$ vektor additive white Gaussian noise dengan rerata nol dan matriks kovarians $\sigma_{\mathbf{n}}^{2} \mathbf{I}_{N N}$. Untuk kondisi array Tx-Rx yang co-located maka vektor steering $\mathrm{Rx} \mathbf{b}(\theta)$ definisinya sama dengan vektor steering $\operatorname{Tx} \mathbf{a}(\theta)$.

Melalui asumsi yang sama dengan radar PA, radar MIMO dengan $M$-unit antena pada Tx memancarkan $M$-buah waveform yang ortogonal satu dengan lain yang selanjutnya diterima oleh $N$-unit antena di Rx. Adanya MF di Rx dapat memisahkan $M$-buah waveform tersebut secara tepat. Sinyal output Rx dari MF membentuk vektor data $M N \times 1$ yaitu [13]

$$
\mathbf{y}_{\text {MIMO }}=\sum_{p=1}^{P} \sigma_{p}\left(\theta_{p}\right) \mathbf{u}_{\text {MIMO }}\left(\theta_{p}\right)+\mathbf{n}_{\text {MIMO }}
$$

dimana $\mathbf{u}_{\text {MIMO }}(\theta)=\mathbf{a}(\theta) \otimes \mathbf{b}(\theta)$ dan $\otimes$ menyatakan operator perkalian Kronecker.

\subsection{FAPES untuk Estimasi Parameter}

Estimasi target $\hat{\sigma}(\theta)$ merupakan estimasi terhadap amplitudo kompleks dari sinyal echo seperti estimator LS. Metode LS ternyata mengalami kelemahan berupa sidelobe yang tinggi dan resolusi rendah. Pada kondisi dengan strong interference dan jamming maka metode LS tidak berfungsi sebagaimana mestinya. Untuk memperoleh estimasi target dengan resolusi tinggi, akurasi estimasi amplitudo tinggi, dan kemampuan menekan interferensi cukup baik maka dapat digunakan metode APES [3]. Bila diketahui sinyal ekuivalen baseband yang diterima oleh $N$-unit elemen antena pada Rx array dengan arah target $\theta_{l}$ dinyatakan dengan vektor 


$$
\mathbf{y}(t)=\sum_{p=1}^{P} \sigma_{p}\left(\theta_{p}\right) \mathbf{b}\left(\theta_{p}\right) \mathbf{a}^{T}\left(\theta_{p}\right) \boldsymbol{\psi}(t)+\mathbf{n}(t)
$$

dengan $(\cdot)^{T}$ adalah operator transpose, $\mathbf{a}(\theta)=\left[\begin{array}{llll}1 & e^{-j 2 \pi d_{M} \sin (\theta) / \lambda} & \cdots & e^{-j 2 \pi(M-1) d_{M} \sin (\theta) \lambda}\end{array}\right]^{T}$ yaitu vektor steering $M \times 1$ pada $\mathrm{Tx}, \mathbf{b}(\theta)=\left[\begin{array}{lllll}1 & e^{-j 2 \pi d_{N} \sin (\theta) \lambda} & \cdots & e^{-j 2 \pi(N-1) d_{N} \sin (\theta) / \lambda}\end{array}\right]^{T}$ yaitu vektor steering $N \times 1$ pada $\mathrm{Rx}, \boldsymbol{\psi}(t)=\left[\begin{array}{llll}\varphi_{1}(t) & \varphi_{2}(t) & \ldots & \varphi_{M}(t)\end{array}\right]^{T}$ yaitu vektor waveform $M \times 1$ dari $\mathrm{Tx}$ dengan $\varphi_{m}(t)$ untuk $m=1,2, \ldots, M$ adalah sinyal baseband transmisi waktu diskrit $t=1, \ldots, Q$, $\sigma_{p}\left(\theta_{p}\right)$ adalah koefisien refleksi radar dari target yang proporsional dengan RCS, $p$ adalah jumlah target yang memantulkan sinyal pantul ke Rx untuk $p=1,2, \ldots, P, \theta_{p}$ adalah lokasi target, dan $\mathbf{n}(t)$ adalah vektor $N \times 1$ dari interference plus noise. Parameter yang akan diestimasi dari $\mathbf{y}(t)$ adalah $\left\{\sigma_{p}\left(\theta_{p}\right)\right\}_{p=1}^{P}$ dan $\left\{\theta_{p}\right\}_{p=1}^{P}$. Jika diasumsikan $\mathbf{n}(t)$ tidak berkorelasi dengan $\boldsymbol{\psi}(t)$ maka sifat identifiabilitas pada suku pertama dari (3) tidak dipengaruhi oleh suku kedua.

Berikut ini tahapan metode APES yang digunakan untuk mengestimasi jumlah target pada radar MIMO dari (3) dapat dilakukan dengan tahapan yaitu: (a) penentuan vektor bobot APES yaitu $\widehat{\mathbf{w}}$ dan (b) estimasi target $\hat{\sigma}(\theta)$ seperti metode LS [3]. Metode APES tersebut dikenal juga sebagai FAPES [8] yang dimanfaatkan untuk aplikasi analisa spektrum sinyal.

Formulasi dari metode FAPES yaitu

$$
\min _{\mathrm{w}, \sigma}\left\|\mathrm{w}^{\mathrm{H}} \mathrm{y}(\mathrm{t})-\sum_{\mathrm{p}=1}^{\mathrm{P}} \sigma_{\mathrm{p}}\left(\theta_{\mathrm{p}}\right) \mathrm{a}^{\mathrm{T}}\left(\theta_{\mathrm{p}}\right) \psi(\mathrm{t})\right\|^{2} \text { terhadap } \mathrm{w}^{\mathrm{H}} \mathrm{b}(\theta)=1
$$

dengan

$$
\begin{gathered}
\left\|\mathrm{w}^{\mathrm{H}} \mathrm{y}(\mathrm{t})-\sum_{\mathrm{p}=1}^{\mathrm{P}} \sigma_{\mathrm{p}}\left(\theta_{\mathrm{p}}\right) \mathrm{a}^{\mathrm{T}}\left(\theta_{\mathrm{p}}\right) \psi(\mathrm{t})\right\|^{2} \\
=\mathrm{w}^{\mathrm{H}} \widehat{\mathrm{R}}_{\mathrm{yy}} \mathrm{w}-\sum_{\mathrm{p}=1}^{\mathrm{P}} \sigma_{\mathrm{p}}^{*}\left(\theta_{\mathrm{p}}\right) \mathrm{w}^{\mathrm{H}} \widehat{\mathrm{R}}_{\mathrm{y} \psi} \mathrm{a}^{*}\left(\theta_{\mathrm{p}}\right)-\sum_{\mathrm{p}=1}^{\mathrm{P}} \sigma_{\mathrm{p}}\left(\theta_{\mathrm{p}}\right) \mathrm{a}^{\mathrm{T}}\left(\theta_{\mathrm{p}}\right) \widehat{\mathrm{R}}_{\psi \mathrm{y}} \mathrm{w} \\
+\sum_{\mathrm{p}=1}^{\mathrm{P}}\left\|\sigma_{\mathrm{p}}\left(\theta_{\mathrm{p}}\right)\right\|^{2} \mathrm{a}^{\mathrm{T}}\left(\theta_{\mathrm{p}}\right) \widehat{\mathrm{R}}_{\psi \psi} \mathrm{a}^{*}\left(\theta_{\mathrm{p}}\right)
\end{gathered}
$$

dan

$$
\begin{aligned}
& \widehat{\mathrm{R}}_{\mathrm{yy}}=\frac{1}{\mathrm{Q}} \sum_{\mathrm{q}=1}^{\mathrm{Q}} \mathrm{y}(\mathrm{q}) \mathrm{y}^{\mathrm{H}}(\mathrm{q}) \\
& \widehat{\mathrm{R}}_{\mathrm{y} \psi}=\frac{1}{\mathrm{Q}} \sum_{\mathrm{q}=1}^{\mathrm{Q}} \mathrm{y}(\mathrm{q}) \psi^{\mathrm{H}}(\mathrm{q}) \\
& \widehat{\mathrm{R}}_{\psi \mathrm{y}}=\frac{1}{\mathrm{Q}} \sum_{\mathrm{q}=1}^{\mathrm{Q}} \psi(\mathrm{q}) \mathrm{y}^{\mathrm{H}}(\mathrm{q}) \\
& \widehat{\mathrm{R}}_{\psi \psi}=\frac{1}{\mathrm{Q}} \sum_{\mathrm{q}=1}^{\mathrm{Q}} \psi(\mathrm{q}) \psi^{\mathrm{H}}(\mathrm{q})
\end{aligned}
$$

dimana $(\cdot)^{H}$ adalah operator Hermitian transpose, $\mathbf{w} \in \boldsymbol{C}^{L \times 1}$ adalah vektor bobot, $Q$ adalah jumlah sampel data, dan $\|\sigma(\theta)\|^{2}=\sigma(\theta) \sigma^{*}(\theta)$. Tujuan dari (2) adalah mendapatkan beamformer yang outputnya serupa dengan sinyal waveform yaitu $\mathbf{a}^{T}(\theta) \psi(t)$.

Selanjutnya meminimumkan (4) yang dijabarkan pada (5) terhadap $\sigma(\theta)$ yaitu dengan mencari diferensial pada (5) yang hasilnya nol akan menjadi

$$
\widehat{\sigma}_{\mathrm{FA}}(\theta)=\frac{\sum_{\mathrm{q}=1}^{\mathrm{Q}} \mathrm{w}^{\mathrm{H}} \widehat{\mathrm{R}}_{\mathrm{Y} \psi} \mathrm{a}^{*}(\theta)}{\mathrm{a}^{\mathrm{T}}(\theta) \widehat{\mathrm{R}}_{\psi \psi} \mathrm{a}^{*}(\theta)}
$$

Serupa ketika mendapatkan (10), maka dilanjutkan meminimumkan (4) terhadap $\mathbf{w}$ akan menghasilkan

$$
0=\mathrm{w}^{\mathrm{H}} \widehat{\mathrm{R}}_{\mathrm{yy}}-\sum_{\mathrm{p}=1}^{\mathrm{P}} \sigma(\theta) \mathrm{a}^{\mathrm{T}}(\theta) \widehat{\mathrm{R}}_{\psi \mathrm{y}}
$$

dan substitusikan (10) ke (11) menghasilkan 


$$
\begin{aligned}
& 0=\mathrm{w}^{\mathrm{H}} \widehat{\mathrm{R}}_{\mathrm{yy}}-\frac{\sum_{\mathrm{p}=1}^{\mathrm{P}} \mathrm{w}^{\mathrm{H}} \widehat{\mathrm{R}}_{\mathrm{y} \psi} \mathrm{a}^{*}(\theta) \mathrm{a}^{\mathrm{T}}(\theta) \widehat{\mathrm{R}}_{\psi \mathrm{y}}}{\mathrm{a}^{\mathrm{T}}(\theta) \widehat{\mathrm{R}}_{\psi \psi} \mathrm{a}^{*}(\theta)} \\
& 0=\widehat{\mathrm{R}}_{\mathrm{yy}} \mathrm{w}-\frac{\sum_{\mathrm{p}=1}^{\mathrm{P}=\widehat{\mathrm{R}}_{\mathrm{y}} \mathrm{a}^{*}(\theta) \mathrm{a}^{\mathrm{T}}(\theta) \widehat{\mathrm{R}}_{\psi \mathrm{y}} \mathrm{w}}}{\mathrm{a}^{\mathrm{T}}(\theta) \widehat{\mathrm{R}}_{\psi \psi} \mathrm{a}^{*}(\theta)}=\widehat{\mathrm{U}}(\theta) \mathrm{w}
\end{aligned}
$$

dengan

$$
\widehat{\mathrm{U}}(\theta)=\widehat{\mathrm{R}}_{\mathrm{yy}}-\frac{\widehat{\mathrm{R}}_{\mathrm{y} \psi} \mathrm{a}^{*}(\theta) \mathrm{a}^{\mathrm{T}}(\theta) \widehat{\mathrm{R}}_{\psi \mathrm{y}}}{\mathrm{a}^{\mathrm{T}}(\theta) \widehat{\mathrm{R}}_{\psi \psi} \mathrm{a}^{*}(\theta)}
$$

Untuk mendapatkan vektor bobot FAPES maka pada (13) dilakukan operasi

$$
\min _{\mathrm{w}} \mathrm{w}^{\mathrm{H}} \widehat{\mathrm{U}}(\theta) \mathrm{w} \quad \text { terhadap } \quad \mathrm{w}^{\mathrm{H}} \mathrm{b}(\theta)=1
$$

dengan meminimumkan (14) terhadap w maka menghasilkan

$$
\widehat{\mathrm{w}}_{\mathrm{FA}}(\theta)=\frac{\widehat{\mathrm{U}}^{-1}(\theta) \mathrm{b}(\theta)}{\mathrm{b}^{\mathrm{H}}(\theta) \widehat{\mathrm{U}}^{-1}(\theta) \mathrm{b}(\theta)}
$$

selanjutnya substitusi (15) ke (10) menjadi

$$
\widehat{\sigma}_{\mathrm{FA}}(\theta)=\frac{\sum_{\mathrm{q}=1}^{\mathrm{Q}} \mathrm{b}^{\mathrm{H}}(\theta) \widehat{\mathrm{U}}^{-1}(\theta) \widehat{\mathrm{R}}_{\mathrm{y} \psi} \mathrm{a}^{*}(\theta)}{\left[\mathrm{b}^{\mathrm{H}}(\theta) \widehat{\mathrm{U}}^{-1}(\theta) \mathrm{b}(\theta)\right]\left[\mathrm{a}^{\mathrm{T}}(\theta) \widehat{\mathrm{R}}_{\psi \psi} \mathrm{a}^{*}(\theta)\right]}
$$

\subsection{FBAPES untuk Estimasi Parameter}

Metode pererataan forward-backward (FB) telah banyak dimanfaatkan untuk meningkatkan kinerja pada aplikasi analisis spektral [8]. Pada Subbab 2.2 telah disajikan estimasi parameter radar MIMO dengan metode FAPES yang menggunakan vektor data dari sinyal yang diterima "maju" (forward) yaitu $\mathbf{y}(q)=\left[\begin{array}{llll}y(q) & y(q+1) & \ldots & y(q+N-1)\end{array}\right]^{T}$. Jika vektor dari sinyal yang diterima "mundur" (backward) yaitu $\hat{\mathbf{y}}(q)=\left[y^{*}(Q-q-1) y^{*}(Q-q-2) \ldots\right.$ $\left.y^{*}(Q-q-\mathrm{N})\right]^{T}$. Berikut adalah perluasan metode FB yang diperkenalkan oleh [8] untuk aplikasi radar MIMO yang merupakan kontribusi utama penelitian ini. Bila dikehendaki output dari data forward dan backward maka formulasinya dinyatakan dengan

$$
\begin{gathered}
\min _{\mathrm{w}, \sigma, \beta} \frac{1}{2 \mathrm{Q}} \sum_{\mathrm{q}=1}^{\mathrm{Q}}\left\|\mathrm{w}^{\mathrm{H}} \mathrm{y}(\mathrm{q})-\sum_{\mathrm{p}=1}^{\mathrm{P}} \sigma_{\mathrm{p}}\left(\theta_{\mathrm{p}}\right) \mathrm{a}^{\mathrm{T}}\left(\theta_{\mathrm{p}}\right) \psi(\mathrm{q})\right\|^{2}\left\|\mathrm{w}^{\mathrm{H}} \hat{\mathrm{y}}(\mathrm{q})-\sum_{\mathrm{p}=1}^{\mathrm{P}} \beta_{\mathrm{p}}\left(\theta_{\mathrm{p}}\right) \mathrm{a}^{\mathrm{T}}\left(\theta_{\mathrm{p}}\right) \psi(\mathrm{q})\right\|^{2} \\
\text { terhadap } \quad \mathrm{w}^{\mathrm{H}} \mathrm{b}(\theta)=1
\end{gathered}
$$

Selanjutnya meminimumkan (17) terhadap $\sigma(\theta)$ dan $\beta(\theta)$ akan menghasilkan berturut-turut pada (10) dan

$$
\widehat{\beta}_{\mathrm{FBA}}(\theta)=\frac{\sum_{\mathrm{q}=1}^{\mathrm{Q}} \mathrm{w}^{\mathrm{H}} \widehat{\mathrm{R}}_{\widehat{y} \psi} \mathrm{a}^{*}(\theta)}{\mathrm{a}^{\mathrm{T}}(\theta) \widehat{\mathrm{R}}_{\psi \psi} \mathrm{a}^{*}(\theta)}
$$

Kemudian meminimumkan (17) terhadap w yang analoginya serupa dengan (11)-(12) akan menghasilkan

$$
\widehat{\mathrm{U}}_{\mathrm{FBA}}(\theta)=\frac{1}{2}\left[\left(\widehat{\mathrm{R}}_{\mathrm{yy}}+\widehat{\mathrm{R}}_{\widehat{\mathrm{y}} \widehat{\mathrm{y}}}\right)-\left(\frac{\widehat{\mathrm{R}}_{\mathrm{y \psi}} \mathrm{a}^{*}(\theta) \mathrm{a}^{\mathrm{T}}(\theta) \widehat{\mathrm{R}}_{\psi \mathrm{y}}}{\mathrm{a}^{\mathrm{T}}(\theta) \widehat{\mathrm{R}}_{\psi \psi} \mathrm{a}^{*}(\theta)}+\frac{\widetilde{\mathrm{R}}_{\widehat{y} \psi} \mathrm{a}^{*}(\theta) \mathrm{a}^{\mathrm{T}}(\theta) \breve{\mathrm{R}}_{\psi \widehat{y}}}{\mathrm{a}^{\mathrm{T}}(\theta) \widehat{\mathrm{R}}_{\psi \psi} \mathrm{a}^{*}(\theta)}\right)\right]
$$

dengan

$$
\begin{aligned}
& \breve{\mathrm{R}}_{\widehat{y} \psi}=\frac{1}{\mathrm{Q}} \sum_{\mathrm{q}=1}^{\mathrm{Q}} \hat{\mathrm{y}}(\mathrm{q}) \psi^{\mathrm{H}}(\mathrm{q}) \\
& \breve{\mathrm{R}}_{\widehat{y} \widehat{y}}=\frac{1}{\mathrm{Q}} \sum_{\mathrm{q}=1}^{\mathrm{Q}} \hat{\mathrm{y}}(\mathrm{q}) \hat{y}^{\mathrm{H}}(\mathrm{q})
\end{aligned}
$$




$$
\breve{\mathrm{R}}_{\psi \widehat{y}}=\frac{1}{\mathrm{Q}} \sum_{\mathrm{q}=1}^{\mathrm{Q}} \psi(\mathrm{q}) \hat{\mathrm{y}}^{\mathrm{H}}(\mathrm{q})
$$

Untuk mendapatkan vektor bobot FBAPES maka pada (19) dilakukan operasi

$$
\min _{\mathrm{w}} \mathrm{w}^{\mathrm{H}} \widehat{\mathrm{U}}_{\mathrm{FBA}}(\theta) \mathrm{w} \text { terhadap } \quad \mathrm{w}^{\mathrm{H}} \mathrm{b}(\theta)=1
$$

dengan meminimumkan (23) terhadap w maka menghasilkan

$$
\widehat{\mathrm{w}}_{\mathrm{FBA}}(\theta)=\frac{\widehat{\mathrm{U}}_{\mathrm{FBA}}^{-1}(\theta) \mathrm{b}(\theta)}{\mathrm{b}^{\mathrm{H}}(\theta) \widehat{\mathrm{U}}_{\mathrm{FBA}}^{-1}(\theta) \mathrm{b}(\theta)}
$$

selanjutnya substitusi (24) ke (10) menjadi

$$
\widehat{\sigma}_{\mathrm{FBA}}(\theta)=\frac{\sum_{\mathrm{q}=1}^{\mathrm{Q}} \mathrm{b}^{\mathrm{H}}(\theta) \widehat{\mathrm{U}}_{\mathrm{FBA}}^{-1}(\theta) \widehat{\mathrm{R}}_{\mathrm{y} \psi} \mathrm{a}^{*}(\theta)}{\left[\mathrm{b}^{\mathrm{H}}(\theta) \widehat{\mathrm{U}}_{\mathrm{FBA}}^{-1}(\theta) \mathrm{b}(\theta)\right]\left[\mathrm{a}^{\mathrm{T}}(\theta) \widehat{\mathrm{R}}_{\psi \psi} \mathrm{a}^{*}(\theta)\right]}
$$

\section{Hasil dan Pembahasan}

Evaluasi kinerja estimasi parameter target dengan metode FAPES dan FBAPES pada radar MIMO berturut-turut menggunakan (16) dan (25) sedangkan metode LS menggunakan (44) pada [6]. Kinerja semua estimator pada dua jenis radar disajikan sebagai grafik modulus amplitudo kompleks (MAK) yang bervariasi terhadap DoA dimana MAK proporsional dengan RCS dinyatakan sebagai $\hat{\sigma}(\theta)$. Bila diasumsikan jumlah elemen antena pada array di Tx-Rx adalah sama, yaitu $M=N=8$ elemen. Spasi antar elemen antena pada array Tx-Rx adalah setengah panjang gelombang. Berikut diulas estimasi parameter target dari sinyal echo pada amplitudo dan fase dari semua estimator yaitu LS, FAPES, dan FBAPES untuk radar multiantena berdasarkan pada besar RCS, resolusi sudut antar dua target, dan jumlah elemen antena di Tx-Rx.

\subsection{Pengaruh Jenis Radar}

Untuk membandingkan kinerja estimator parameter antara metode yang diusulkan yaitu FBAPES, dengan metode yang lain, yaitu LS dan FAPES, pada kedua jenis radar multi-antena, yaitu PA dan MIMO, maka diasumsikan ada tiga target berlokasi di $\Theta_{\mathrm{A}}=\left\{-35^{\circ}, 4^{\circ}, 18^{\circ}\right\}$ dengan amplitudo kompleks yang proporsional dengan RCS untuk semua target yaitu $\sigma\left(\Theta_{\mathrm{A}}\right)=1$. Pada Gambar 1(a)-(b) menunjukkan MAK untuk kinerja semua estimator yang diterapkan seperti LS, FAPES, dan FBAPES pada dua jenis radar yaitu PA dan MIMO.

Untuk radar MIMO, kinerja estimator-estimator tersebut secara umum mampu mendeteksi ketiga target dengan tepat seperti pada Gambar 1(a) baik dalam deteksi MAK yaitu mendekati nilai $\mathrm{RCS}=1$ dan semua DoA pada $\Theta_{\mathrm{A}}$ terdeteksi dengan tepat. Sebaliknya pada radar PA di Gambar 1(b), hanya estimator LS yang berfungsi mendeteksi ketiga target walaupun MAK memiliki resolusi yang tidak tepat bahkan terdapat sidelobe yang tinggi. Hal ini diulas lebih lanjut pada Subbab 3.4 yang menunjukkan pengaruh jumlah elemen array di Tx-Rx terhadap kinerja estimator. Radar PA termasuk memiliki jumlah waveform yang ditransmit paling sedikit yaitu semua elemen pada array di Tx, yaitu $M=8$, memancarkan satu waveform saja sehingga sulit untuk mendeteksi banyak target apalagi untuk deteksi DoA maupun MAK yang tepat. Hal tersebut sejalan dengan studi yang dilaporkan oleh [11] yaitu kemampuan deteksi semakin meningkat dengan naiknya jumlah subarray dimana untuk radar PA subarray-nya bernilai 1 sedangkan radar MIMO memiliki subarray sebanyak $M$-buah. Untuk radar MIMO kemampuan deteksi target tinggi karena semua elemen antena pada array di Tx memancarkan $M$-buah waveform sehingga berdampak pada tingginya peragaman waveform seperti yang telah dibahas oleh [6].

Tampak juga dari Gambar 1(a), bahwa dengan menggunakan estimator FAPES dan FBAPES memiliki resolusi sudut DoA untuk deteksi lokasi target-target $\Theta_{\mathrm{A}}$ lebih akurat dibanding metode LS. Meskipun dari sisi akurasi MAK pada metode LS relatif lebih baik (lihat Gambar 1(b)). Khusus pada radar MIMO di Gambar 1(a), tidak serupa dengan metode LS, 
kedua estimator APES hampir tidak memiliki sidelobe sehingga kondisi ini menguntungkan bila berhadapan dengan strong interference dan jamming. Kondisi dan kemampuan estimator APES tersebut sejalan dengan hasil yang diperoleh oleh [11] mengenai penekanan terhadap sidelobe.

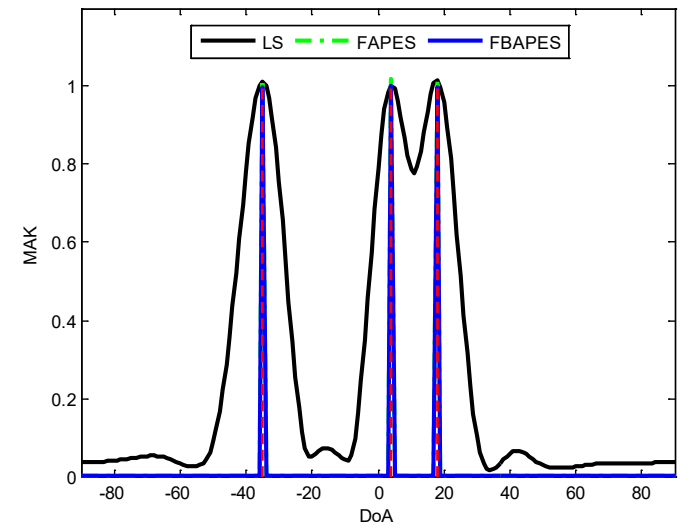

(a)

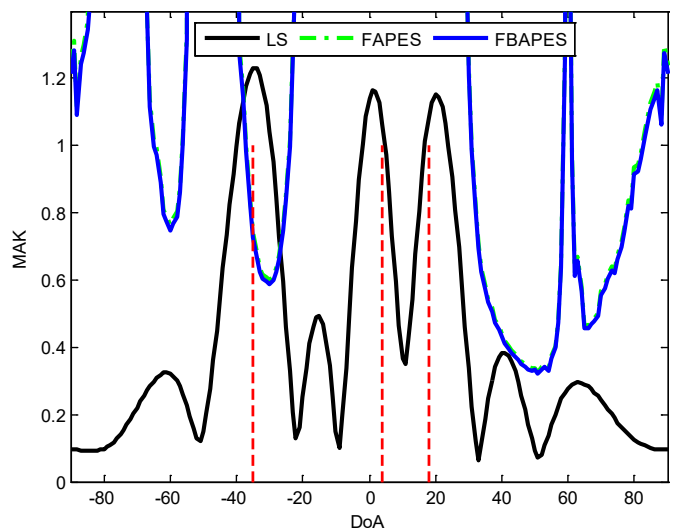

(b)

Gambar 1. Modulus amplitudo kompleks (MAK) dari berbagai estimator dengan $\Theta_{\mathrm{A}}$ dan RCS sama untuk: (a) radar MIMO dan (b) radar PA.

Kedua estimator APES unggul dalam hal deteksi DoA dibanding metode LS (lihat Gambar 1(a)). Untuk melihat kelebihan akurasi deteksi DoA pada kedua estimator APES tersebut maka dibandingkan dari kemampuan estimasi amplitudonya. Hasil deteksi amplitudo MAK untuk $\Theta_{\mathrm{A}}$ pada ketiga estimator untuk radar MIMO tertabulasi pada Tabel 1. Metode membandingkan kinerja ketiga estimator tersebut dengan menggunakan pendekatan Root Mean Square Error (RMSE) terhadap modulus dari amplitudo kompleks sasaran yaitu RCS bernilai 1. RMSE bisa dinyatakan dengan

$$
\mathrm{RMSE}=\sqrt{\frac{1}{\mathrm{~K}} \sum_{\mathrm{k}=1}^{\mathrm{K}}\left(\theta_{0}-\theta_{\mathrm{k}}\right)^{2}}
$$

dimana $K$ adalah banyak data perhitungan, $\theta_{\mathrm{o}}$ dan $\theta_{k}$ berturut-turut adalah data MAK dari DoA yang dikehendaki dan data MAK dari DoA yang terukur.

Tabel 1. Perbandingan kinerja deteksi amplitudo dari semua estimator dengan RCS bernilai 1.

\begin{tabular}{cccc}
\hline DoA $\left(^{\circ}\right)$ & LS & FAPES & FBAPES \\
\hline-35 & 1,015 & 1,020 & 1,000 \\
4 & 1,000 & 1,020 & 0,998 \\
18 & 1,015 & 1,020 & 0,995 \\
\hline
\end{tabular}

Untuk Tabel 1 maka diperoleh RMSE dari MAK untuk estimator LS, FAPES, dan FBAPES berturut-turut adalah 0,$012 ; 0,020$; dan 0,008 . Untuk kondisi kasus sudut $\Theta_{\mathrm{A}}$ ternyata persentase RMSE dari MAK pada estimator FBAPES lebih rendah dibanding FAPES yaitu $0,8 \%$ berbanding 2,0\%. Terbukti dari hasil perhitungan RMSE bahwa kinerja estimator FBAPES lebih superior dibanding FAPES. Hal ini juga mendukung hasil studi yang dilaporkan oleh [9] dimana kinerja estimator FBAPES memiliki bias dalam estimasi amplitudo 0,41 kali dari yang diperoleh FAPES.

\subsection{Pengaruh Variasi RCS}

Berdasarkan ulasan pada Bagian 3.1 tentang kinerja radar PA, untuk kondisi RCS yang bervariasi maka perbandingan kinerja estimator dari metode yang diusulkan terhadap metode yang lain hanya diterapkan pada radar MIMO saja. Jika diasumsikan ada empat target berlokasi di $\Theta_{\mathrm{B}}=\left\{-45^{\circ}, 5^{\circ}, 15^{\circ}, 35^{\circ}\right\}$ dengan amplitudo kompleks yang proporsional dengan RCS untuk 
semua target berturut-turut yaitu $\{2 ; 1 ; 1,5 ; 0,5\}$ yang disajikan pada Gambar 2. Pembahasan di bagian ini merupakan kelanjutan dari Subbab 3.1 yaitu melihat keunggulan ketiga metode dalam estimasi amplitudo dan DoA.

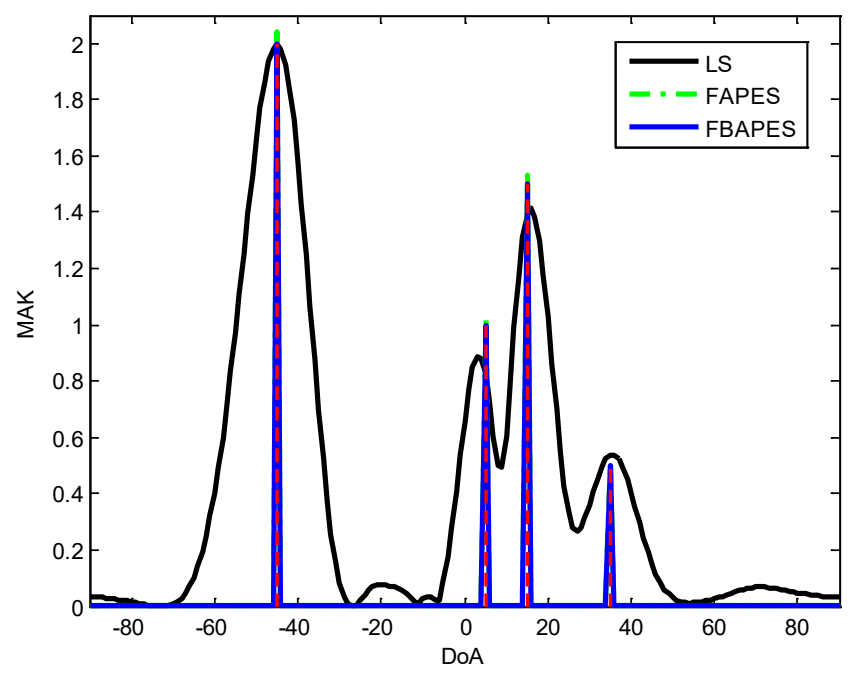

Gambar 2. MAK dari radar MIMO untuk berbagai estimator dengan $\Theta_{\mathrm{B}}$ dan RCS bervariasi.

Tampak dari Gambar 2 bahwa kemampuan deteksi DoA kedua metode APES lebih akurat dibanding metode LS meskipun ketiga estimator tersebut bisa mendeteksi keempat target yang diberikan. Tabel 2 menyajikan data pengukuran dari MAK untuk $\Theta_{\mathrm{B}}$ pada semua estimator untuk radar MIMO. Untuk nilai RMSE dari MAK untuk estimator LS, FAPES, dan FBAPES berturut-turut diperoleh nilai 0,282; 0,027; dan 0,004. Untuk kondisi kasus sudut $\Theta_{\mathrm{B}}$ tersebut ternyata persentase RMSE dari MAK pada estimator FBAPES lebih rendah dibanding FAPES yaitu $0,4 \%$ berbanding $2,7 \%$. Hasil ini juga menunjukkan keunggulan kinerja estimator FBAPES dibanding FAPES yang mendukung hasil studi yang dilaporkan oleh [9].

Tabel 2. Perbandingan kinerja deteksi amplitudo dari semua estimator dengan RCS bervariasi.

\begin{tabular}{ccccc}
\hline DoA $\left({ }^{\circ}\right)$ & RCS & LS & FAPES & FBAPES \\
\hline-45 & 2 & 1,989 & 2,040 & 1,995 \\
5 & 1 & 0,889 & 1,020 & 0,998 \\
15 & 1,5 & 2,053 & 1,530 & 1,495 \\
35 & 0,5 & 0,530 & 0,498 & 0,499 \\
\hline
\end{tabular}

\subsection{Resolusi Sudut Deteksi}

Jika diberikan dua DoA yaitu $\theta_{1}$ dan $\theta_{2}$ dan $\delta_{\theta}=\left(\theta_{2}-\theta_{1}\right)$, suatu radar memiliki resolusi sudut yang baik jika $\delta_{\theta}$ bernilai sangat kecil dengan nilai minimal $\delta_{\theta}>0$. $\delta_{\theta}$ yang kecil menunjukkan seberapa mampu radar untuk membedakan dua lokasi DoA target yang sangat berdekatan. Pada Gambar 3 jika diasumsikan DoA untuk $\theta_{1}=0^{\circ}$ dan $\theta_{2}=3^{\circ}$ maka resolusinya $\delta_{\theta}=3^{\circ}$. Tampak pada Gambar 3 tersebut bahwa estimator LS tidak mampu mendeteksi kedua DoA tersebut yang berarti resolusi sudut estimatornya rendah. Sebaliknya pada kedua varian estimator APES mampu mendeteksi kedua target DoA dengan resolusi amplitudonya mendekati 1 yaitu untuk FAPES dan FBAPES berturut-turut adalah 1,023 dan 0,998. Hal ini sejalan dengan studi yang dilaporkan oleh [7] bahwa kedua varian estimator APES memiliki resolusi sudut yang superior dibanding LS. 


\subsection{Pengaruh Jumlah Elemen Antena di Tx-Rx}

Untuk mempertimbangkan pengaruh ukuran elemen antena pada kinerja estimator terutama estimator yang diusulkan yaitu FBAPES maka dilakukan pengamatan terhadap berbagai ukuran $M$ dan $N$ pada Tx-Rx radar MIMO. Ukuran $M$ dan $N$ adalah sama dari 2 hingga 12 elemen dengan asumsi DoA yaitu $\Theta_{\mathrm{C}}=\left\{-50^{\circ},-30^{\circ},-20^{\circ}, 10^{\circ}, 30^{\circ}, 40^{\circ}\right\}$ dan RCS satu semua. Tampak pada Gambar 4 bahwa kemampuan estimator FBAPES untuk mendeteksi DoA dan amplitudo target cenderung tepat bila ukuran $M=N$ naik. Pada kondisi $M=N$ yaitu $2 \leq(M=N)<6$ elemen maka target $\Theta_{\mathrm{C}}$ hanya mampu terdeteksi 2 hingga 3 target. Sementara untuk kondisi $(M$ $=N) \geq 6$ maka target $\Theta_{\mathrm{C}}$ mampu terdeteksi dengan baik oleh estimator FBAPES baik pada jumlah DoA, MAK, dan resolusinya. Hasil dan analisa ini juga menegaskan bahwa memang benar estimator tersebut tidak berfungsi pada radar PA dan seiring bertambahnya jumlah elemen $M$ dan $N$ maka kemampuan estimator juga meningkat seperti yang ditunjukkan pada kinerja radar MIMO.

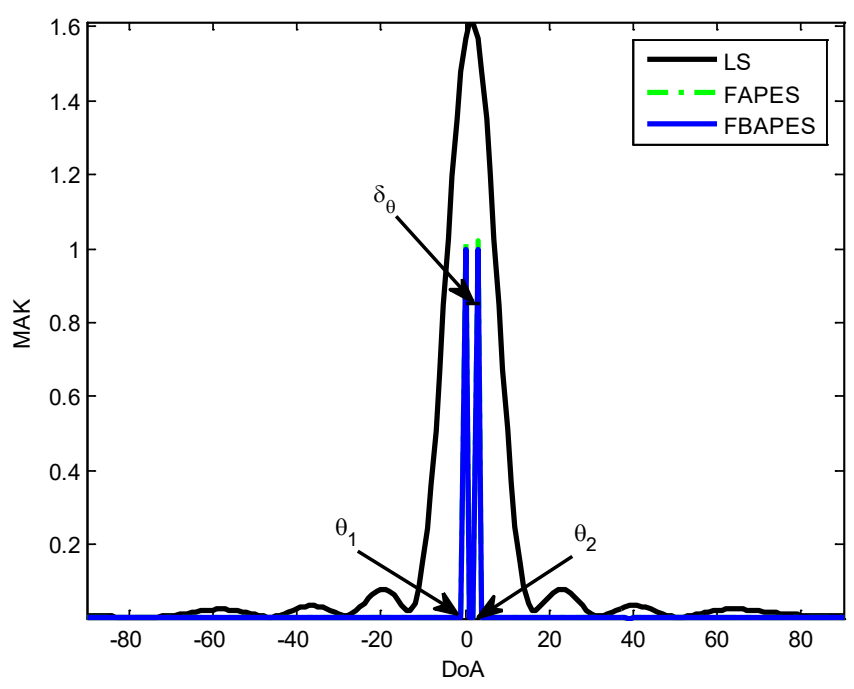

Gambar 3. MAK pada radar MIMO untuk berbagai estimator yang ber-RCS $=1$ dengan $\delta_{\theta}=\left(\theta_{2}-\theta_{1}\right)$.

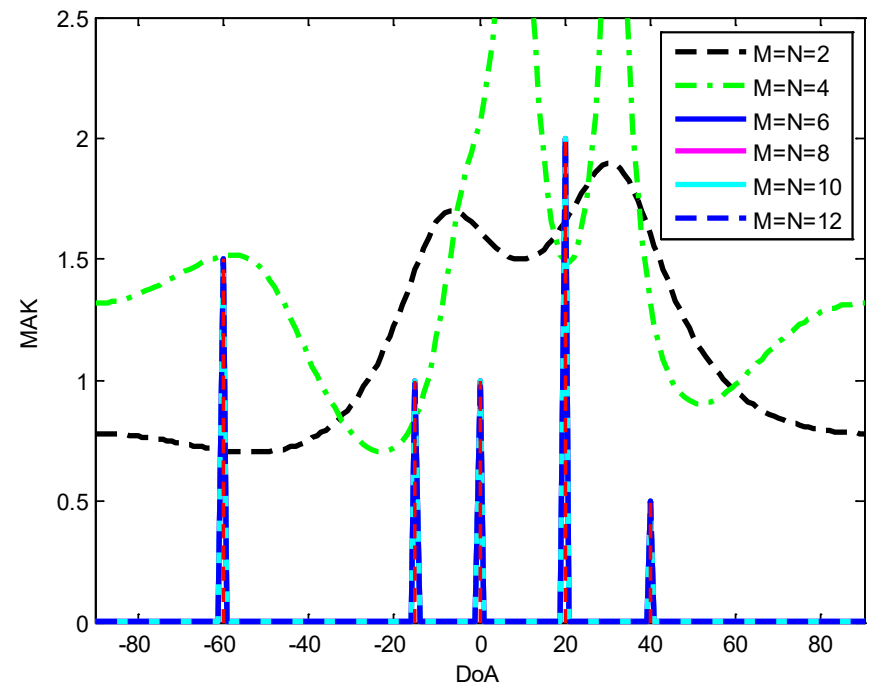

Gambar 4. MAK pada radar MIMO khusus estimator FBAPES dengan $\Theta_{\mathrm{C}}$ dan variasi $M=N$ di Tx-Rx. 


\section{Kesimpulan}

Makalah ini telah memformulasi dan mengevaluasi estimasi parameter dari deteksi target dengan metode FBAPES. Kinerja estimasi tersebut telah dibandingkan dengan estimasi konvensional seperti LS dan FAPES dengan mempertimbangkan faktor-faktor seperti jenis radar (PA dan MIMO), variasi RCS, resolusi sudut antara dua target, dan jumlah elemen antena di Tx-Rx. Semua estimator, yaitu LS, FAPES, dan FBAPES, bekerja dengan baik jika diterapkan pada radar MIMO namun tidak dengan radar PA karena hanya estimator LS yang berfungsi mendeteksi ketiga target walaupun MAK memiliki resolusi yang tidak tepat. Kemampuan deteksi DoA kedua metode APES lebih akurat dibanding metode LS dimana estimator FBAPES memiliki RMSE separuh lebih rendah dari yang diperoleh FAPES. Resolusi sudut deteksinya lebih baik dari estimator LS, sebagai contoh untuk $M=N=8$ maka diperoleh resolusi sudut $3^{\circ}$ sedangkan estimator LS sebesar 5,8 $8^{\circ}$. Kemampuan estimator FBAPES untuk mendeteksi DoA dan amplitudo target cenderung tepat bila ukuran $M=N$ naik. Untuk pertimbangan aplikasi dan desain sistem radar terutama ketika berhadapan dengan strong interference dan jamming, kedua varian estimator APES memiliki resolusi sudut DoA dan MAK yang bagus dan tanpa sidelobe sehingga kondisi ini menguntungkan untuk para desainer radar.

\section{Referensi}

[1] H. N. R A K, "Desain antena hexagonal patch array untuk peningkatan gain dan bandwidth pada frekuensi 2,4 GHz," TELKA: Jurnal Telekomunikasi, Elektronika, Komputasi, dan Kontrol, vol.2, no.1, pp. 44-52, Mei 2016.

[2] M. I. Skolnik, Introduction to Radar Systems, 3rd ed. McGraw-Hill, New York, USA, 2001.

[3] J. Li and P. Stoica, MIMO Radar Signal Processing, John Wiley \& Sons, Hoboken, NJ, 2009.

[4] S. Tahcfulloh and G. Hendrantoro, "Full phased MIMO radar with colocated antennas," International Journal on Communications Antenna and Propagation, vol. 9, no. 2, pp. 144-154, Jul. 2019.

[5] M. Hardiwansyah, S. Tahcfulloh, and G. Hendrantoro, "Parameter identifiability of phased-MIMO radar," In Proc. International Conference of Artificial Intelligence and Information Technology, Mar. 2019, pp. 192-195.

[6] S. Tahcfulloh and G. Hendrantoro, "FPMIMO: a general MIMO structure with overlapping subarrays for various radar applications," IEEE Access, vol. 8, pp. 11248-11267, Jan. 2020.

[7] X. Luzhou, J. Li, and P. Stoica, "Target detection and parameter estimation for MIMO radar systems," IEEE Transactions on Aerospace and Electronic Systems, vol. 44, no. 3, pp. 927-939, Jul. 2008.

[8] P. Stoica, H. Li, and J. Li, "A new derivation of the APES filter," IEEE Signal Processing Letters, vol. 6, no. 8, Aug. 1999.

[9] H. Li, J. Li, and P. Stoica, "Performance analysis of forward-backward matchedfilterbank spectral estimators," IEEE Transactions on Signal Processing, vol. 46, no. 7, pp. 1954-1966, Jul. 1998.

[10] P. Stoica and R. L. Moses, Spectral Analysis of Signals, Prentice-Hall, Upper Saddle River, NJ.

[11] S. Tahcfulloh and M. Hardiwansyah, "Parameter estimation and target detection of phased-MIMO radar using capon estimator," Jurnal Elektronika dan Telekomunikasi, vol. 20, no. 2, pp. 60-69, Dec. 2020.

[12] C. Gao, H. Zhou, R. Wu, X. Xu, F. Shen, and Z. Guo, "Parameter estimation and multi-pulse target detection of radar MIMO," In Proc. IEEE Region 10 Conference, Nov. 2016, pp. 909-914.

[13] S. Tahcfulloh, and G. Hendrantoro, "Phased MIMO radar with coherent receive 
arrays," In Proc. International Conference on Signals and Systems, May 2017, pp. $72-$ 76.

[14] S. Tahcfulloh, "SMIMO radar: MIMO radar with subarray elements of phased-array antenna," International Journal of Information Technology and Electrical Engineering, vol. 5, no. 2, pp. 37-44, Jun. 2021. 